\title{
Apparent diffusion coefficient for molecular subtyping of non-gadolinium-enhancing WHO grade II/III glioma: volumetric segmentation versus two-dimensional region of interest analysis
}

\author{
S. C. Thust ${ }^{1,2,3} \cdot$ S. Hassanein ${ }^{1,3} \cdot$ S. Bisdas ${ }^{1,3} \cdot$ J. H. Rees ${ }^{4} \cdot$ H. Hyare ${ }^{1,2}$ - J. A. Maynard ${ }^{2} \cdot$ S. Brandner $^{5} \cdot$ C. Tur $^{6}$. \\ H. R. Jäger ${ }^{1,2,3} \cdot$ T. A. Yousry ${ }^{1,3} \cdot$ L. Mancini $^{1,3}$
}

Received: 17 October 2017 / Revised: 26 December 2017 / Accepted: 23 January 2018 / Published online: 23 March 2018

(C) The Author(s) 2018. This article is an open access publication

\begin{abstract} gadolinium-enhancing gliomas, comparing whole tumour against single slice analysis. $\mathrm{ADC}_{\text {mean }}$ in the tumour and normal appearing white matter was calculated for both methods. $91 \%(100 \%)$ and AUC of 0.95 (0.96). The intraclass correlation coefficient was excellent (0.98). yielded similar results in this study.

Key Points

- Diffusion-weighted MRI aids the identification of non-gadolinium-enhancing malignant gliomas

- ADC measurements may permit non-gadolinium-enhancing glioma molecular subtyping

- IDH wild-type gliomas have lower ADC values than IDH-mutant tumours

- Single cross-section and volumetric ADC measurements yielded comparable results in this study
\end{abstract}

Objectives To investigate if quantitative apparent diffusion coefficient (ADC) measurements can predict genetic subtypes of non-

Methods Volumetric T2-derived masks of 44 gliomas were co-registered to ADC maps with $\mathrm{ADC}$ mean $\left(\mathrm{ADC} \mathrm{mean}_{\text {m }}\right.$ calculated. For the slice analysis, two observers placed regions of interest in the largest tumour cross-section. The ratio $\left(\mathrm{ADC}_{\mathrm{ratio}}\right)$ between

Results Isocitrate dehydrogenase (IDH) wild-type gliomas showed the lowest ADC values throughout $(p<0.001)$. ADC mean in the IDH-mutant 1p19q intact group was significantly higher than in the IDH-mutant 1p19q co-deleted group ( $p<0.01)$. A volumetric $\mathrm{ADC}_{\text {mean }}$ threshold of $1201 \times 10^{-6} \mathrm{~mm}^{2} / \mathrm{s}$ identified IDH wild-type with a sensitivity of $83 \%$ and a specificity of $86 \%$; a volumetric $\mathrm{ADC}_{\text {ratio }}$ cut-off value of 1.65 provided a sensitivity of $80 \%$ and a specificity of $92 \%$ (area under the curve (AUC) 0.9-0.94). A slice $\mathrm{ADC}_{\text {ratio }}$ threshold for observer 1 (observer 2) of 1.76 (1.83) provided a sensitivity of $80 \%$ (86\%), specificity of

Conclusions ADC measurements can support the distinction of glioma subtypes. Volumetric and two-dimensional measurements

Keywords Brain · Diffusion magnetic resonance imaging $\cdot$ Isocitrate dehydrogenase $\cdot$ Glioma $\cdot$ Neuroimaging

$\begin{aligned} & \text { Abbreviations } \\ & \text { ADC }\end{aligned}$
$\begin{aligned} & \text { AUC } \\ & \text { CS } \\ & \text { Area under the curve } \\ & \text { Centrum semiovale }\end{aligned}$
$\begin{aligned} & \text { S. C. Thust } \\ & \text { s.thust @ ucl.ac.uk }\end{aligned}$
Neuroradiological Academic Unit, Department of Brain Repair and
Rehabilitation, UCL Institute of Neurology, London, UK
2 Imaging Department, University College London Foundation
Hospital, London, UK

$\begin{array}{ll}\text { DKI } & \text { Diffusion kurtosis imaging } \\ \text { DTI } & \text { Diffusion tensor imaging } \\ \text { DWI } & \text { Diffusion-weighted imaging } \\ \text { IDH } & \text { Isocitrate dehydrogenase }\end{array}$

3 Lysholm Department of Neuroradiology, National Hospital for Neurology and Neurosurgery, Queen Square, London WC1N 3BG, UK

4 Department of Clinical Neurology, National Hospital for Neurology and Neurosurgery, London, UK

5 Department of Neurodegenerative Disease, UCL Institute of Neurology and Division of Neuropathology, London, UK

6 Queen Square MS Centre. Department of Neuroinflammation, UCL Institute of Neurology, University College London, London, UK 


\begin{tabular}{|c|c|}
\hline $\mathrm{IDH}^{\mathrm{wt}}$ & Isocitrate dehydrogenase wild-type \\
\hline $\mathrm{IDH}^{\mathrm{mut}} 1 \mathrm{p} 19^{\text {int }}$ & $\begin{array}{l}\text { Isocitrate dehydrogenase-mutant } 1 \mathrm{p} 19 \mathrm{q} \\
\text { intact }\end{array}$ \\
\hline $\mathrm{IDH}^{\mathrm{mut}} 1 \mathrm{p} 19^{\mathrm{del}}$ & $\begin{array}{l}\text { Isocitrate dehydrogenase-mutant } 1 \mathrm{p} 19 \mathrm{q} \text { co- } \\
\text { deleted }\end{array}$ \\
\hline ICC & Intraclass correlation coefficient \\
\hline LGG & Low grade glioma \\
\hline NAWM & Normal appearing white matter \\
\hline $\mathrm{ACS}$ & $\begin{array}{l}\text { Picture archiving and communications } \\
\text { system }\end{array}$ \\
\hline $\mathrm{OC}$ & Receiver operating characteristic \\
\hline $\mathrm{OI}_{\mathrm{CS}}$ & Centrum semiovale region of interest \\
\hline $\mathrm{ROI}_{\text {tum }}$ & Tumour region of interest \\
\hline $\mathrm{TE}$ & Echo time \\
\hline TR & Repetition time \\
\hline $\mathrm{VOI}_{\mathrm{CS}}$ & Centrum semiovale volume of interest \\
\hline $\mathrm{VOI}_{\text {tum }}$ & Tumour volume of interest \\
\hline $\mathrm{HO}$ & World Health Organization \\
\hline $4 G$ & D2-hydroxyglutarate \\
\hline
\end{tabular}

\section{Introduction}

Gadolinium contrast uptake was previously considered the best MR imaging predictor of glioma histological grade and malignancy[1-3]. On the basis of this, it has been common practice to interpret non-enhancing intrinsic tumours as probable low grade gliomas (LGG) [4]. But conventional MRI has proven to be unreliable in predicting subsequent tumour behaviour, whereby a proportion of presumed LGG may rapidly progress with development of malignant features such as enhancement and necrosis [4-8].

The discovery of several key genetic alterations as principal determinants of glioma prognosis has challenged the reference standard of glioma grouping by histology [9]. Mutations in isocitrate dehydrogenase (IDH) represent a common (> 70\%) defining event in the development of LGG, conversely more than $90 \%$ of glioblastomas belong to the IDH wild-type group [10, 11]. Despite its oncogenic effect through production of a toxic metabolite D2hydroxyglutarate (2HG), the presence of an IDH mutation is associated with a favourable prognosis.

The revised 2016 World Health Organization (WHO) classification of brain tumours for the first time incorporates molecular data to augment the diagnosis [12]. For WHO grade II/ III gliomas, three molecular subgroups have been defined: IDH wild-type glioma (IDH ${ }^{\mathrm{wt}}$ ) with survival similar to that of glioblastoma, IDH-mutant glioma with intact $1 p 19 q$ $\left(\mathrm{IDH}^{\mathrm{mut}} 1 \mathrm{p} 19^{\text {int }}\right)$ and an intermediate prognosis, and IDHmutant $1 \mathrm{p} 19 \mathrm{q}$ co-deleted glioma $\left(\mathrm{IDH}^{\mathrm{mut}} 1 \mathrm{p} 19 \mathrm{q}^{\mathrm{del}}\right)$ with the best prognosis and greatest chemosensitivity [11]. There is partial overlap with histomorphology, whereby many $\mathrm{IDH}^{\mathrm{mut}} 1 \mathrm{p} 19^{\mathrm{int}}$ are astrocytic and the majority of
$\mathrm{IDH}^{\mathrm{mut}} 1 \mathrm{p} 19 \mathrm{q}^{\mathrm{del}}$ belong to the oligodendroglioma group [13]. IDH $^{\mathrm{wt}}$ gliomas probably constitute a genetically heterogeneous category of lesions, but often exhibit aggressive behaviour and have been suspected to represent early glioblastoma [14-17]. In the emerging literature on MR imaging features of $\mathrm{IDH}^{\mathrm{wt}}$ glioma, initial lack of enhancement has been reported in some of these tumours $[6,18,19]$.

Diffusion-weighted imaging (DWI) is a technique of great interest in cancer, because water diffusivity is impaired in highly cellular tissues, which reflects tumour proliferative rate and aggressiveness [20]. The phenomenon of reduced diffusion preceding fulminant radiological progression of presumed LGG has been observed prior to molecular typing [7], evoking later descriptions of IDH $^{\mathrm{wt}}$ glioma serial imaging findings [4]. Quantitative apparent diffusion coefficient (ADC) values have demonstrated high accuracy for glioma grading through meta-analysis [21]. For the non-invasive identification of low to intermediate $\mathrm{IDH}^{\mathrm{wt}}$ glioma, diffusion tensor imaging (DTI) and diffusion kurtosis imaging (DKI) have shown potential, suggesting that reduced and heterogenous diffusivity are $\mathrm{IDH}^{\mathrm{wt}}$ features [22-24]. However, advanced diffusion techniques are not universally available outside academic hospital institutions, may require longer scan times and dedicated post-processing.

Mean ADC measurement could be a rapid and practicable approach to assess glioma diffusivity, being computationally non-demanding compared to histograms or texture analysis. Although theoretically superior, there is no conclusive evidence that whole lesion analysis outperforms region-ofinterest placement for the identification of malignant gliomas [25].

The study presented sought to (i) investigate whether ADC measurements from routine clinical DWI were associated with glioma molecular subtype and (ii) to compare the performance of volumetric whole tumour ADC with single slice ADC measurements.

\section{Materials and methods}

\section{Patients}

Following institutional board approval for a retrospective study, we searched the neuropathology records revealing 37 patients with WHO grade II/III IDH ${ }^{\text {wt }}$ glioma between 2009 and 2016. For comparison of the molecular groups, control samples of IDH (IDH1-R132H) mutant gliomas (34 $\mathrm{IDH}^{\mathrm{mut}} 1 \mathrm{p} 19 \mathrm{q}^{\text {int }}$ and $\left.32 \mathrm{IDH}^{\mathrm{mut}} 1 \mathrm{p} 19 \mathrm{q}^{\mathrm{del}}\right)$ were randomly selected. We sought to evaluate ADC for suspected LGG prior to tissue diagnosis. To replicate the clinical situation, only gliomas without gadolinium enhancement were included (2 non-enhancing gliomas were excluded because of missing images and degraded DWI, respectively). The study sample 
consisted of $14 \mathrm{IDH}^{\mathrm{wt}}$ (7 WHO II and 7 WHO III), 16 IDH $^{\text {mut }} 1 \mathrm{p} 19 \mathrm{q}^{\text {int }}$ ( 8 WHO II and 8 WHO III) and 14 $\mathrm{IDH}^{\mathrm{mut}} 1 \mathrm{p} 19 \mathrm{q}^{\mathrm{del}}$ (11 WHO II and 3 WHO III), amounting to 44 non-enhancing gliomas for the three molecular groups (patient selection diagram shown in Fig. 1). No haemorrhagic or necrotic gliomas were featured in the study.

\section{MRI acquisition}

Ours is a quaternary neurosurgical centre; therefore the standard (structural and DWI) MRI sequences in this study originated from 10 different referring institutions (institution 1 to institution 10): 29 from our own institutions, 4 from institution 2, 3 from institution 3, 2 from institution 4, and one each from the remaining six institutions. The studies were acquired on 18 different scanners (31 at 1.5 Tesla, and 13 at 3 Tesla) from all major vendors: four General Electric scanners [Discovery MR450 (number of patients $n=5$ ), $2 \times$ Signa Excite $(n=1$ each), Genesis Signa $(n=2)]$, seven Siemens scanners $[3 \times$ Avanto $(n=7, n=2, n=1)$, a Trio $(n=9)$, Symphony $(n=$ 4), Skyra $(n=3)$, Espree $(n=1)$ ], six Philips scanners [Ingenia $(n=2), 5 \times$ Achieva $(n=1$ each $)]$ and one Toshiba scanner $(n=$ 1). All acquisitions included axial T2-weighted images, and axial standard 3-directional whole brain DWI. The median [min, max] values of the parameters of the T2-weighted images were echo time $(\mathrm{TE})=99.5[80,141] \mathrm{ms}$; repetition time $(\mathrm{TR})=4610[2500,7480] \mathrm{ms}$, in-plane resolution $=0.5 \times 0.5$ $[0.3 \times 0.3,0.9 \times 0.9] \mathrm{mm}^{2}$; slice thickness $=5[1,6] \mathrm{mm}$; gap between slices $=1.5[0,2] \mathrm{mm}$. All DWI acquisitions included diffusion gradient weighting values $b=0 \mathrm{~s} / \mathrm{mm}^{2}$ and $b=1000$ $\mathrm{s} / \mathrm{mm}^{2}$; the median [min, $\left.\max \right]$ of other parameters were $\mathrm{TE}=$
$90.5[69.5,137] \mathrm{ms} ; \mathrm{TR}=4000[2837,10,000] \mathrm{ms}$, in-plane resolution $=1.25 \times 1.25[0.5 \times 0.5,2.5 \times 2.5] \mathrm{mm}^{2}$; slice thickness $=5[4,6] \mathrm{mm}$; gap between slices $=1.5[0,2]$ $\mathrm{mm}$. For each patient, the imaging study was performed on average (standard deviation, sd) 2.3 (2.8) months prior to the tissue diagnosis. Image examples for the glioma molecular subgroups are shown in Fig. 2.

\section{Post-processing and ADC analysis}

\section{ADC map calculation}

In a spin echo diffusion-weighted sequence, the signal $S_{\mathrm{b}}\left[S_{\mathrm{b}}=\right.$ $\left.S_{0} \mathrm{e}^{(-b \text { ADC })}\right]$ from each pixel in an image is formed of a first component $\left(S_{0}\right)$ dependent on tissue properties (i.e. 'spin density', $\mathrm{T}_{1}$ and $\mathrm{T}_{2}$ relaxation times) and sequence properties (e.g. repetition time, TR); and a second component $\left(\mathrm{e}^{-b \mathrm{ADC}}\right) \mathrm{de}-$ pendent on the diffusion gradients $\left(b\right.$, in units of $\left.\mathrm{s} / \mathrm{mm}^{2}\right)$ and the apparent diffusion coefficient (ADC, in units of $\mathrm{mm}^{2} / \mathrm{s}$ ).

The ADC is obtained by dividing the image acquired without diffusion gradients $\left(S_{b=0}=\mathrm{S}_{0}\right)$ by the image acquired with diffusion gradients $\left(S_{\mathrm{b}}\right)$ :

$\mathrm{ADC}=(1 / b) \ln \left(S_{0} / S_{\mathrm{b}}\right)$

In this division, the dependence of $\mathrm{ADC}$ from $\mathrm{S}_{0}$ (and therefore from $\mathrm{T}_{1}, \mathrm{~T}_{2}$ and $\mathrm{TR}$ ) is eliminated [26]. The ADC maps were calculated using Eq. 1 and the utility fslmaths from the software library fsl (version 5.0) [27]. Offline whole tumour analysis and single slice analysis were subsequently performed.
Fig. 1 Flow diagram of patients included and excluded from the analyses

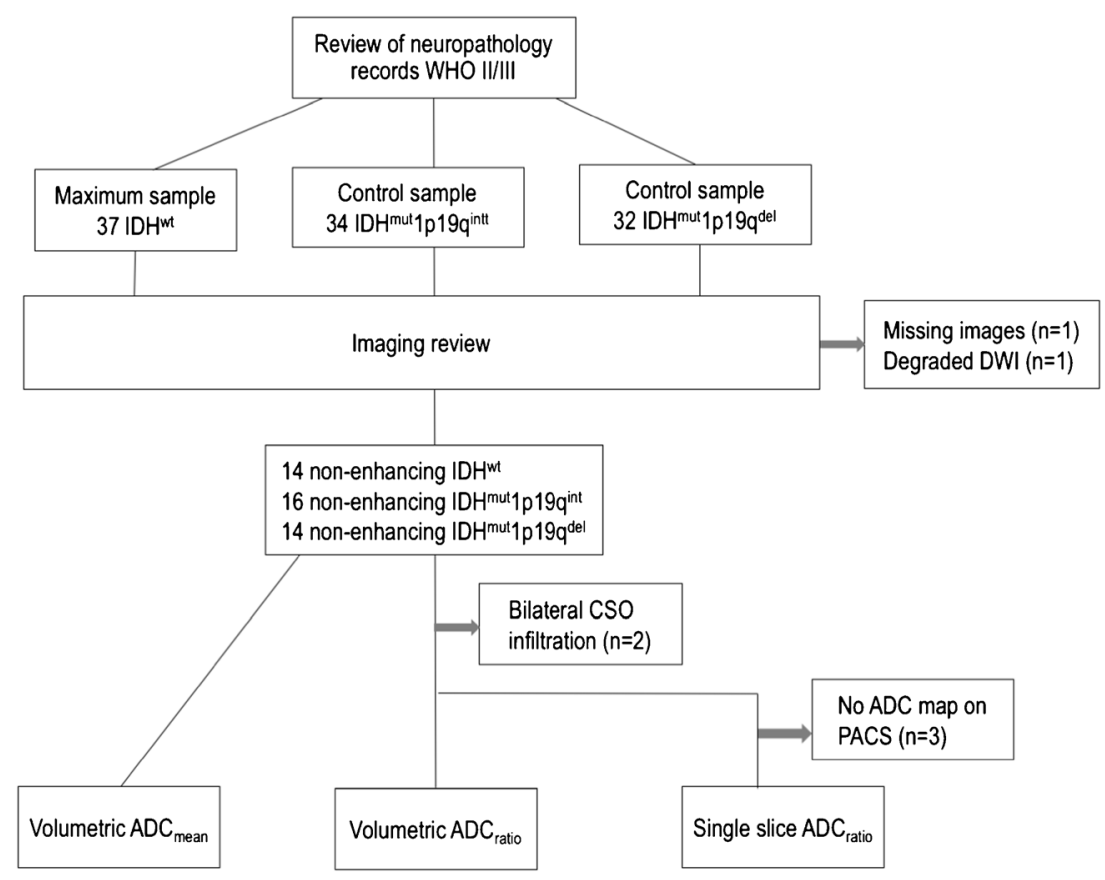


Fig. 2 WHO II/III molecular subgroup examples showing T2weighted images, $b 1000$, ADC maps and T1-weighted post gadolinium images of nonenhancing $\mathbf{a} \mathrm{IDH}^{\mathrm{wt}}, \mathbf{b}$ $\mathrm{IDH}^{\mathrm{mut}} 1 \mathrm{p} 19 \mathrm{q}^{\text {int }}$ and $\mathbf{c}$ IDH $^{\text {mut }} 1$ p19q ${ }^{\text {del }}$ glioma

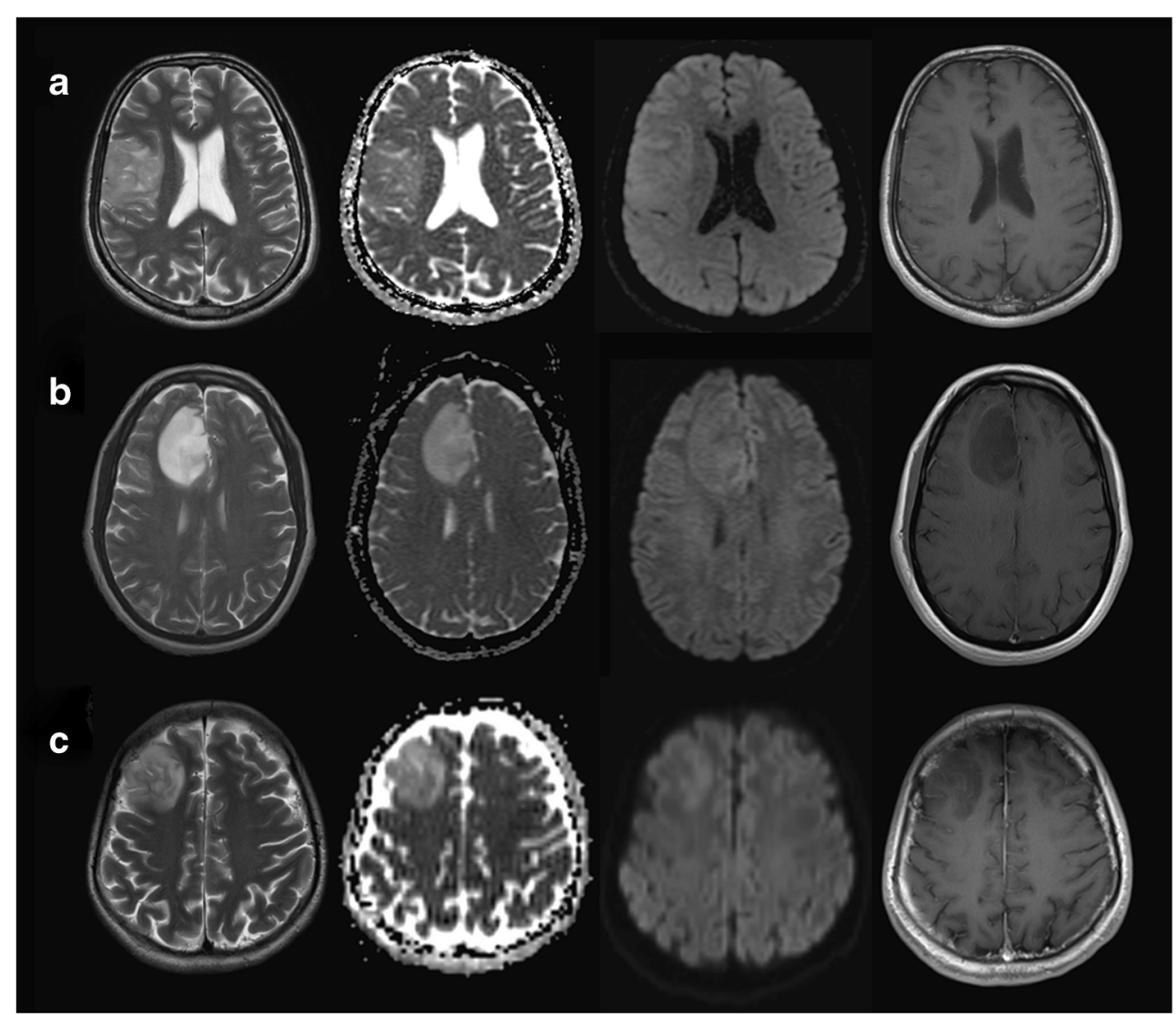

\section{Whole tumour (volumetric) ADC analysis}

Tumour volumes of interest $\left(\mathrm{VOI}_{\text {tum }}\right)$ were outlined by a neuroradiology resident (S.H.) using ITK snap Toolbox version 3.6 (www.itksnap.org [28]), covering the entire T2 signal abnormality with each segmentation optimised by a board-certified neuroradiologist specialised in brain tumour imaging (S.C.T.). For multicentric gliomas, the total volume of signal abnormality was treated as one lesion. ADC maps were co-registered to T2 imaging using the FLIRT toolbox $[29,30]$ performing a rigid body transformation with a six-parameter model and 'Normalised Mutual Information' as cost function. Subsequently, $\mathrm{ADC}_{\text {mean }}$ measurements were obtained for each tumour, using the fslstats utility from fsl [25-27].

To consider possible interindividual variations in brain diffusivity, we assessed the $\mathrm{ADC}_{\text {mean }}$ in normal appearing white matter (NAWM). For each patient, a standardised second volume of interest $\left(\mathrm{VOI}_{\mathrm{CS}}\right)$ was drawn in the contralateral centrum semiovale $(\mathrm{CS})$. This $\mathrm{VOI}_{\mathrm{CS}}$ was used to calculate the $\mathrm{ADC}_{\text {ratio }}=\mathrm{ADC}_{\text {mean }}\left(\mathrm{VOI}_{\text {tum }}\right) /$ $\mathrm{ADC}_{\text {mean }}\left(\mathrm{VOI}_{\mathrm{CS}}\right.$ ) (Fig. 2). For two $\mathrm{IDH}^{\mathrm{wt}}$ tumours, the NAWM analysis was omitted because of bilateral tumour infiltration.

\section{Single slice ADC analysis}

Standard picture archiving and communication systems (PACS) software (IMPAX 6.5.1.1008, Agfa-Gevaert, Mortsel, Belgium) was used to exploit tools routinely available for reporting of MR images. Two observers blinded to histomolecular results (J.A.M. general radiology trainee $=$ observer 1 and S.C.T. $=$ observer 2) located the tumour on the T2weighted sequence, selecting two round regions of interest on the ADC map viewed side-by-side: The first region of interest (ROI $\mathrm{I}_{\text {tum }}$ ) was drawn in the largest lesion cross-section sparing the tumour margin to avoid partial volume effects. The second round $\mathrm{ROI}_{\mathrm{CS}}$ aiming for a similar size to $\mathrm{ROI}_{\text {tum }}$ was placed in contralateral centrum semiovale NAWM, taking care to exclude images with visible ventricular surfaces, cortex and/or sulcal spaces at measurement level. Three patients were excluded from the single slice analysis because of non-availability of an $\mathrm{ADC}$ map on PACS. The ratio between the $\mathrm{ADC}_{\text {mean }}$ in the tumour and $\mathrm{CS}$ was calculated $\left[\mathrm{PACS} \mathrm{ADC}_{\text {ratio }}=\right.$ $\left.\mathrm{ADC}_{\text {mean }}\left(\mathrm{ROI}_{\text {tum }}\right) / \mathrm{ADC}_{\text {mean }}\left(\mathrm{ROI}_{\mathrm{CS}}\right)\right]$. No absolute $\mathrm{ADC}$ values were measured by the single slice method, as their workstation display can vary depending on the referring institution. An example of the volumetric segmentation and single slice ADC measurement is demonstrated in Fig. 3. 
Fig. 3 Image examples demonstrating the whole lesion volumetric segmentation (mask overlaid on right frontal $\mathrm{IDH}^{\text {mut }} 1 \mathrm{p} 19 \mathrm{q}^{\text {int }}$ glioma), single slice largest tumour cross-section $\mathrm{ROI}_{\text {tum }}$ and comparative contralateral NAWM ROI ${ }_{\mathrm{CS}}$ placements

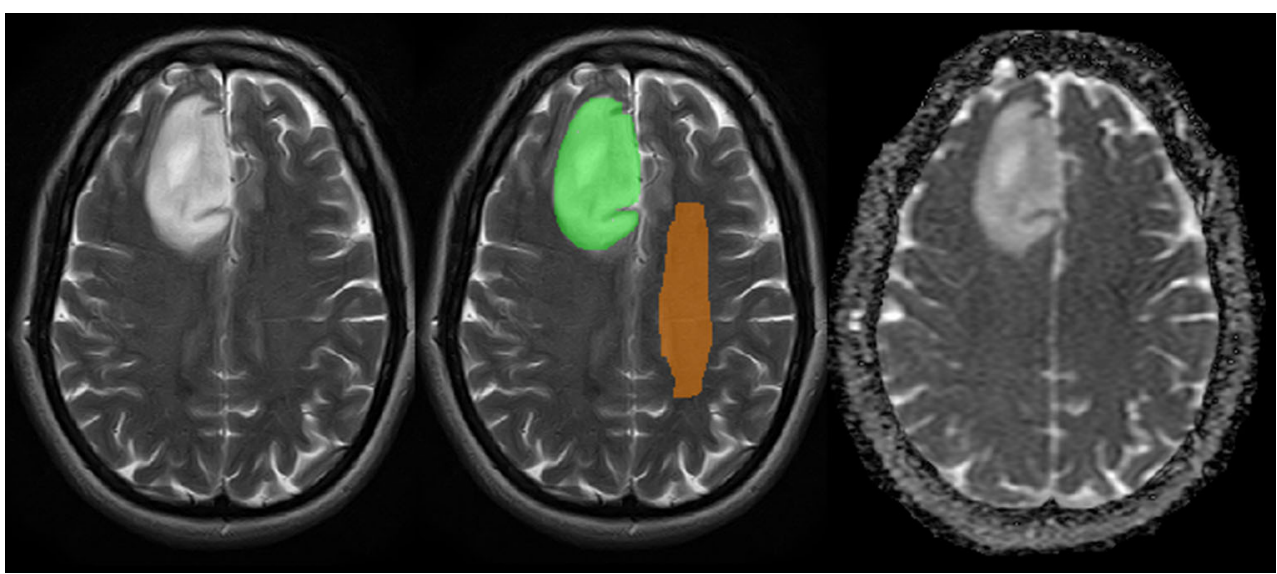

\section{Histopathology and molecular analysis}

Paraffin blocks containing tissue were analysed at our institution's neuropathology department according to WHO 2016 guidance and previously published data [16]. IDH R132H immuno-negative tumours underwent multiple gene Sanger sequencing. A quantitative polymerase chain reaction-based copy number assay was used to determine $1 \mathrm{p} / 19 \mathrm{q}$ status.

\section{Statistical analysis}

For the volumetric and single slice data, the statistical analysis consisted of two steps each: (i) linear regression to assess the association between the tumour type (IDH ${ }^{\mathrm{wt}}, \mathrm{IDH}^{\mathrm{mut}} 1 \mathrm{p} 19 \mathrm{q}^{\mathrm{int}}$, $\mathrm{IDH}^{\mathrm{mut}} 1 \mathrm{p} 19 \mathrm{q}^{\mathrm{del}}$ ) and ADC values, followed by (ii) logistic regression to determine if ADC values can differentiate $\mathrm{IDH}^{\mathrm{wt}}$ from $\mathrm{IDH}^{\mathrm{mut}}$ gliomas. A receiver operating characteristic (ROC) analysis was used to quantify the performance of the logistic regression. For the identification of a cut-off point for the logistic regression the 'nearest to $(0,1)$ ' method was performed. Statistical significance was set at $5 \%$. The interrater agreement was expressed as an intraclass correlation coefficient (ICC) using a two-way random effects model. All statistical analyses were performed using Stata version 14 (College Station, TX: StataCorp LP).

\section{Results}

The mean age was greater in the $\mathrm{IDH}^{\mathrm{wt}}$ group than in the $\mathrm{IDH}^{\text {mut }}$ groups $\left(p=0.0001\right.$ for $\mathrm{IDH}^{\text {mut }} 1 \mathrm{p} 19 \mathrm{q}^{\text {int }}, p=0.005$ for $\left.\mathrm{IDH}^{\mathrm{mut}} 1 \mathrm{p} 19 \mathrm{q}^{\mathrm{del}}\right)$. The larger proportion of WHO II gliomas in the IDH ${ }^{\text {mut }} 1 p 19 q^{\text {del }}$ was not statistically significant (Pearson chi-square test $p=0.115$ for $\mathrm{IDH}^{\mathrm{wt}}$ and $p=0.105$ for $\left.\mathrm{IDH}^{\mathrm{mut}} 1 \mathrm{p} 19 \mathrm{q}^{\mathrm{int}}\right)$. The patient demographic data and tumour volumes are reported in Table 1.

\section{Association between molecular subtype and ADC values}

In the volumetric analysis, $\mathrm{IDH}^{\mathrm{wt}}$ tumours showed significantly lower whole tumour volume $\mathrm{ADC}_{\text {mean }}\left(\mathrm{VOI}_{\text {tum }}\right)$ than $\mathrm{IDH}^{\text {mut }} 1 \mathrm{p} 19 \mathrm{q}^{\text {int }}(p<0.0005)$ and $\mathrm{IDH}^{\text {mut }} 1 \mathrm{p} 19 \mathrm{q}^{\text {del }}(p=0.001)$. The $\mathrm{ADC}_{\text {mean }}\left(\mathrm{VOI}_{\text {tum }}\right)$ in the $\mathrm{IDH}^{\mathrm{mut}} 1 \mathrm{p} 19 \mathrm{q}^{\text {int }}$ group was significantly higher than in the $\operatorname{IDH}^{\text {mut }} 1 \mathrm{p} 19 \mathrm{q}^{\text {del }}$ group $(p=0.0047)$.

$\mathrm{IDH}^{\mathrm{wt}}$ gliomas had a significantly lower whole tumour $\mathrm{ADC}_{\text {ratio }}$ than $\mathrm{IDH}^{\mathrm{mut}} 1 \mathrm{p} 19 \mathrm{q}^{\mathrm{int}}(p<0.0005)$ and $\mathrm{IDH}^{\mathrm{mut}} 1 \mathrm{p} 19 \mathrm{q}^{\mathrm{del}}(p=0.019)$. The $\mathrm{ADC}_{\text {ratio }}$ in the $\mathrm{IDH}^{\text {mut }} 1 \mathrm{p} 19 \mathrm{q}^{\text {int }}$ group was significantly higher than in the $\mathrm{IDH}^{\text {mut }} 1 \mathrm{p} 19 \mathrm{q}^{\text {del }}$ group $(p=0.0054)$.

On single slice assessment, a significantly lower mean

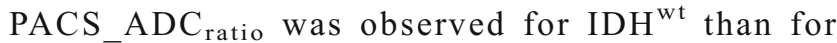

Table 1 Patient demographic data and tumour volumes

\begin{tabular}{llllll}
\hline Whole tumour $\mathrm{ADC}_{\text {mean }}\left(\mathrm{VOI}_{\mathrm{tum}}\right)$ & & & \\
\hline Patient group & $\begin{array}{l}\text { Nr of patients } \\
\text { total }(\text { male })\end{array}$ & $\begin{array}{l}\text { Age in years } \\
(\text { mean } \pm \mathrm{sd})(\text { years })\end{array}$ & $\begin{array}{l}\text { Tumour volume } \\
(\text { mean } \pm \mathrm{sd})\left(\mathrm{cm}^{3}\right)\end{array}$ & $\begin{array}{l}\text { CS NAWM volume } \\
(\text { mean } \pm \mathrm{sd})\left(\mathrm{cm}^{3}\right)\end{array}$ & $\begin{array}{l}\text { Tumour volume for patients } \\
\text { with bilateral infiltration } \\
(\mathrm{mean} \pm \mathrm{sd})\left(\mathrm{cm}^{3}\right)\end{array}$ \\
\hline $\mathrm{IDH}^{\mathrm{wt}}$ & $14(9)$ & $53( \pm 14)$ & $64( \pm 68)(n=12)$ & $11.6( \pm 2.5)(n=12)$ & $366( \pm 46)(n=2)$ \\
$\mathrm{IDH}^{\text {mut }} 1 \mathrm{p} 19^{\text {int }}$ & $16(6)$ & $33.9( \pm 8.6)$ & $60( \pm 44)$ & $10.9( \pm 2.3)$ & $\mathrm{N} / \mathrm{A}$ \\
$\mathrm{IDH}^{\text {mut }} 1 \mathrm{p} 19^{\text {del }}$ & $14(7)$ & $38.9( \pm 8.3)$ & $48( \pm 50)$ & $10.8( \pm 2.5)$ & $\mathrm{N} / \mathrm{A}$ \\
\hline
\end{tabular}


$\mathrm{IDH}^{\mathrm{mut}} 1 \mathrm{p} 19 \mathrm{q}^{\mathrm{int}}(p<0.0005$ observer $1 ; p<0.0005$ observer 2) and for $\operatorname{IDH}^{\mathrm{mut}} 1 \mathrm{p} 19 \mathrm{q}^{\mathrm{del}}(p=0.001$ observer $1 ; p=0.001$ observer 2). The PACS_ADC ${ }_{\text {ratio }}$ in the $\mathrm{IDH}^{\text {mut }} 1 \mathrm{p} 19 \mathrm{q}^{\text {int }}$ group was higher than in the IDH ${ }^{\text {mut }} 1 \mathrm{p} 19 \mathrm{q}^{\mathrm{del}}$ group $(p=0.0008$ for observer 1 and $p=0.0025$ for observer 2 ). No statistical associations were demonstrated between the NAWM $\mathrm{ADC}_{\text {mean }}$ values and molecular subtype.

The intra-rater agreement for the PACS_ADC ${ }_{\text {ratio }}$ measurements was very high: the correlation of measurements made on the same individual was 0.96 , while the correlation between mean observer ratings was 0.98 . The correlation of measurements equaled the consistency agreement, indicating no systematic difference between the two observers. The single slice $\mathrm{ADC}_{\text {ratio }}$ values were slightly but systematically higher than the volumetric $\mathrm{ADC}_{\text {ratio }}$. The numerical results of the association between tumour type and ADC values for the volumetric and single slice analyses are reported in Table 2 . In Table 3, the difference between the ADC values in $\mathrm{IDH}^{\mathrm{mut}} 1 \mathrm{p} 19 \mathrm{q}^{\mathrm{int}}$ and in $\mathrm{IDH}^{\mathrm{mut}} 1 \mathrm{p} 19 \mathrm{q}^{\mathrm{del}}$ is shown. In Table 4 the ICC values are detailed. The boxplots of the $\mathrm{ADC}_{\text {mean }}$ and $\mathrm{ADC}_{\text {ratio }}$ values are depicted in Fig. 4.
Table $3 \quad F$ test for the difference between $\mathrm{IDH}^{\mathrm{mut}} 1 \mathrm{p} 19^{\mathrm{int}}$ and $\mathrm{IDH}^{\text {mut }} 1 \mathrm{p} 19^{\text {del }}$

\begin{tabular}{|c|c|}
\hline Analysis type & $p$ \\
\hline $\mathrm{ADC}_{\text {mean }}\left(\mathrm{VOI}_{\mathrm{tum}}\right)$ & 0.0047 \\
\hline Whole tumour $\mathrm{ADC}_{\text {ratio }}$ & 0.0054 \\
\hline PACS_ADC ratio $_{1 \text { st observer }}$ & 0.0008 \\
\hline PACS_ADC ratio $_{2} 2$ nd observer & 0.0025 \\
\hline
\end{tabular}

\section{Diagnostic performance of ADC values}

For $\mathrm{ADC}_{\text {mean }}\left(\mathrm{VOI}_{\text {tum }}\right)$, a ROC analysis quantified the accuracy of correctly classifying tumour type to an area under the curve (AUC) of 0.94. The cut-off point for the $\mathrm{ADC}_{\text {mean }}\left(\mathrm{VOI}_{\text {tum }}\right)$ was $1201 \times 10^{-6} \mathrm{~mm}^{2} / \mathrm{s}$, with a sensitivity of 0.83 and a specificity of 0.86 . For a decrease in the $\mathrm{ADC}_{\text {mean }}\left(\mathrm{VOI}_{\text {tum }}\right)$ value by $1.0 \times$ $10^{-5} \mathrm{~mm}^{2} / \mathrm{s}$, the odds of $\mathrm{IDH}^{\mathrm{wt}}$ increased by $78 \%(p=0.003)$.

For the volumetric $\mathrm{ADC}_{\text {ratio, }}$, the ROC analysis yielded an AUC of 0.90 with a sensitivity of 0.80 and a specificity of 0.92 for a threshold $\mathrm{ADC}_{\text {ratio }}$ of 1.65 . For a decrease in the volumetric $\mathrm{ADC}_{\text {ratio }}$ value by 0.1 , the odds of $\mathrm{IDH}^{\mathrm{wt}}$ increased by $46 \%(p=0.004)$.

Table 2 Results of the linear regression between ADC and tumour type (IDH ${ }^{\mathrm{wt}}$ is the reference group)

\begin{tabular}{|c|c|c|c|c|}
\hline \multicolumn{5}{|c|}{ Whole tumour $\mathrm{ADC}_{\text {mean }}\left(\mathrm{VOI}_{\text {tum }}\right)$} \\
\hline Patient group & $\begin{array}{l}\mathrm{ADC}_{\text {mean }}\left(\mathrm{VOI}_{\text {tum }}\right) \\
\text { mean }(\mathrm{sd}) \\
\left(10^{-6} \mathrm{~mm}^{2} / \mathrm{s}\right)\end{array}$ & $\begin{array}{l}\text { Regression } \\
\text { coefficient } \\
\left(10^{-6} \mathrm{~mm}^{2} / \mathrm{s}\right)\end{array}$ & $\begin{array}{l}95 \% \text { CI of the } \\
\text { regr. coeff. } \\
\left(10^{-6} \mathrm{~mm}^{2} / \mathrm{s}\right)\end{array}$ & $p$ \\
\hline $\mathrm{IDH}^{\mathrm{wt}}$ & $1032(168)$ & 1032 & $922-1141$ & 0.0005 \\
\hline $\mathrm{IDH}^{\mathrm{mut}} 1 \mathrm{p} 19^{\mathrm{int}}$ & $1543(254)$ & 511 & $361-661$ & 0.0005 \\
\hline $\mathrm{IDH}^{\mathrm{mut}} 1 \mathrm{p} 19^{\mathrm{del}}$ & $1321(162)$ & 289 & $134-444$ & 0.001 \\
\hline \multicolumn{5}{|c|}{ Whole tumour $\mathrm{ADC}_{\text {ratio }}$} \\
\hline Patient group & $\begin{array}{l}\mathrm{ADC}_{\text {ratio }} \\
\text { mean }(\mathrm{sd})\end{array}$ & $\begin{array}{l}\text { Regression } \\
\text { coefficient }\end{array}$ & $\begin{array}{l}95 \% \text { CI of the } \\
\text { regr. coeff. }\end{array}$ & $p$ \\
\hline $\mathrm{IDH}^{\mathrm{wt}}$ & $1.49(0.32)$ & 1.49 & $1.32-1.66$ & 0.0005 \\
\hline $\mathrm{IDH}^{\mathrm{mut}} 1 \mathrm{p} 19^{\mathrm{int}}$ & $2.09(0.34)$ & 0.59 & $0.37-0.82$ & 0.0005 \\
\hline $\mathrm{IDH}^{\mathrm{mut}} 1 \mathrm{p} 19^{\mathrm{del}}$ & $1.77(0.20)$ & 0.28 & $0.05-0.51$ & 0.019 \\
\hline \multicolumn{5}{|c|}{ Single slice PACS_ADC ratio $_{\text {first observer }}$} \\
\hline Patient group & $\begin{array}{l}\text { PACS_ADC }{ }_{\text {ratio }} \\
\text { mean (sd) }\end{array}$ & $\begin{array}{l}\text { Regression } \\
\text { coefficient }\end{array}$ & $\begin{array}{l}95 \% \text { CI of the } \\
\text { regr. coeff. }\end{array}$ & $p$ \\
\hline $\mathrm{IDH}^{\mathrm{wt}}$ & $1.50(0.21)$ & 1.50 & $1.33-1.68$ & 0.0005 \\
\hline $\mathrm{IDH}^{\mathrm{mut}} 1 \mathrm{p} 19^{\mathrm{int}}$ & $2.37(0.35)$ & 0.87 & $0.63-1.10$ & 0.0005 \\
\hline $\mathrm{IDH}^{\mathrm{mut}} 1 \mathrm{p} 19^{\mathrm{del}}$ & $1.96(0.27)$ & 0.45 & $0.20-0.70$ & 0.001 \\
\hline \multicolumn{5}{|c|}{ Single slice PACS_ADC ratio $_{\text {sio }}$ second observer } \\
\hline Patient group & $\begin{array}{l}\text { PACS_ADC } \text { ratio }_{\text {}} \\
\text { mean (sd) }\end{array}$ & $\begin{array}{l}\text { Regression } \\
\text { coefficient }\end{array}$ & $\begin{array}{l}95 \% \text { CI of the } \\
\text { regr. coeff. }\end{array}$ & $p$ \\
\hline $\mathrm{IDH}^{\mathrm{wt}}$ & $1.48(0.19)$ & 1.48 & $1.28-1.68$ & 0.0005 \\
\hline $\mathrm{IDH}^{\mathrm{mut}} 1 \mathrm{p} 19^{\text {int }}$ & $2.37(0.38)$ & 0.88 & $0.62-1.14$ & 0.0005 \\
\hline $\mathrm{IDH}^{\mathrm{mut}} 1 \mathrm{p} 19^{\mathrm{del}}$ & $1.96(0.36)$ & 0.47 & $0.20-0.75$ & 0.001 \\
\hline
\end{tabular}

Regression coefficient represents the difference in the dependent variable (ADC) between each of the two IDH ${ }^{\text {mut }}$ groups and the reference group $\left(\mathrm{IDH}^{\mathrm{wt}}\right)$ 
Table 4 Inter-rater agreement expressed as intraclass correlation coefficient (ICC)

Correlation ICC

$(95 \% \mathrm{CI})$

Consistency ICC (95\% CI)

\begin{tabular}{lcc} 
Observer 1 vs observer 2 & PACS_ADC & \\
Individual ICC & $0.96(0.92-0.98)$ & $0.96(0.92-0.98)$ \\
Average ICC & $0.98(0.96-0.99)$ & $0.98(0.96-0.99)$ \\
Observer 1 PACS_ADC ratio & Vs volumetric ADC $_{\text {ratio }}$ & \\
Individual ICC & $0.80(0.35-0.92)$ & $0.87(0.77-0.93)$ \\
Average ICC & $0.89(0.52-0.96)$ & $0.93(0.87-0.96)$ \\
Observer 2 PACS_ADC & \\
Indivio vs volumetric ADC & \\
Average ICC & $0.79(0.43-0.91)$ & $0.85(0.74-0.92)$ \\
& $0.88(0.60-0.95)$ & $0.92(0.85-0.96)$ \\
\hline
\end{tabular}

A ROC analysis quantified the accuracy of the

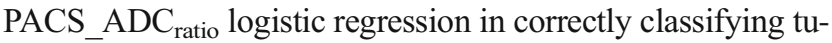
mour type to an AUC of 0.96 for observer 1 and 0.95 for observer 2. The cut-off point for the PACS_ADC $C_{\text {ratio }}$ for observer 1 (observer 2) was 1.83 (1.76) with a sensitivity of 0.80 $(0.86)$ and a specificity of $1.00(0.91)$ at the cut-off point. For a decrease in the single slice $\mathrm{ADC}_{\text {ratio }}$ value by 0.1 , the odds of $\mathrm{IDH}^{\mathrm{wt}}$ increased by $62 \%(p=0.005)$ for observer 1 and $57 \%$ $(p=0.004)$ for observer 2 . The numerical results for glioma subtype prediction are reported in Table 5. The ROC curves are depicted in Fig. 5.

\section{Discussion}

In this analysis, we observed that ADC values obtained from standard clinical DWI are a highly significant predictor of non-enhancing glioma IDH status and may permit noninvasive molecular subtyping in accordance with the 2016 WHO classification.

Two recent surveys highlighted clinical practices in caring for patients with presumed LGG, with approximately $50 \%$ of neurosurgeons adopting a 'wait and see' approach balanced against surgical risk [31], and only $21 \%$ performing an upfront biopsy [32]. Consequently, innocuous appearing $\mathrm{IDH}^{\mathrm{wt}}$ gliomas may reveal their aggressive nature through progression and receive treatment with a delay.

Low ADC values are associated with increased glioma cellularity and worse prognosis, supported by comparisons of diffusivity, histological specimens and clinical data in multiple studies [5, 33-37]. Low diffusivity predicts poor astrocytoma survival independent from WHO grade [38], although no linear relation exists between ADC and glioma prognosis [39].

Past studies to distinguish astrocytoma and oligodendroglioma using $\mathrm{ADC}$ values yielded variable success [40, 41], and in retrospect may have been influenced by the incomplete overlap between histological and molecular groups. Diagnostic focus has shifted to genetic typing, yet immunohistochemistry tests are complex and not infallible, requiring interpretation in in the context of morphological criteria and test type performed to avoid interpretational errors [42].
Fig. 4 Boxplot of the values of the a whole tumour $\mathrm{ADC}_{\text {mean }}\left(\mathrm{VOI}_{\text {tum }}\right), \mathbf{b}$ whole tumour $\mathrm{ADC}_{\text {ratio }}$, c single slice PACS $\mathrm{ADC}_{\text {ratio }}$ first observer and d single slice PACS_ADC ratio first observer

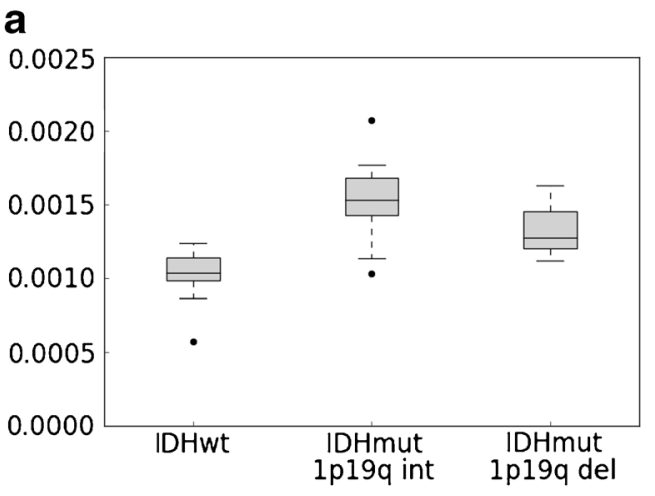

C

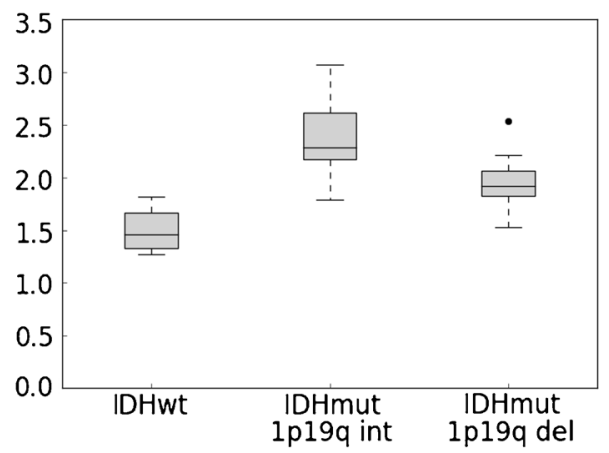

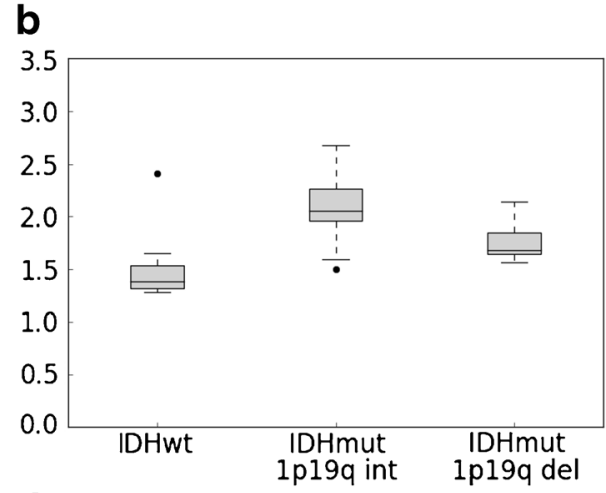

d

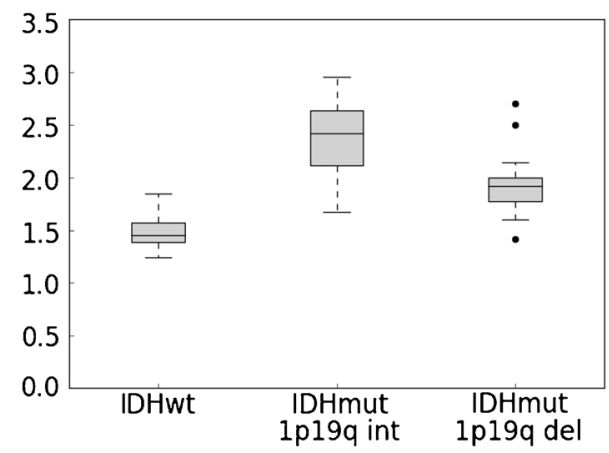


Table 5 Cut-off point estimation

\begin{tabular}{lclll}
\hline Method & Cut-off point & Sensitivity at cut-off point & Specificity at cut-off point & AUC at cut-off point \\
\hline ADC ${ }_{\text {mean }}\left(\mathrm{VOI}_{\text {tum }}\right)$ & 1201 & 0.83 & 0.86 & 0.85 \\
Whole tumour ADC $_{\text {ratio }}$ & $\left(10^{-6} \mathrm{~mm}^{2} / \mathrm{s}\right)$ & & 0.92 & 0.86 \\
PACS_ADC & 1.65 & 0.80 & 1.00 & 0.93 \\
PACS_ADC ratio $_{\text {ratio }}$ 2nd observer & 1.83 & 0.86 & 0.91 & 0.88 \\
\hline
\end{tabular}

Recently, Leu et al. were able to assign gliomas to the WHO 2016 molecular groups using ADC; however, their method differed from ours by including enhancing lesions and ADC median values derived from $b 700-1000$ gradients with DTI analysed for some patients [43]. To our best knowledge, this is the first IDH typing study to focus on non-enhancing gliomas, using $b 1000$ values derived from 3-directional DWI. This is particularly important, as such tumours are usually assumed to be less aggressive in common clinical practice.

We found $\mathrm{ADC}_{\text {ratio }}$ values to be closely reproducible when comparing whole lesion measurements against single slice region of interest placements, for which there was near complete interobserver agreement. The similarity of our volumetric and single slice results could be explained by a relative homogeneity of these non-enhancing, non-necrotic gliomas. Both the absolute $\mathrm{ADC}_{\text {mean }}$ values and $\mathrm{ADC}_{\text {ratio }}$ appear valuable for this lesion type. The quicker and easier single slice analysis even performed marginally better. This is in line with results of previous imaging research, which suggested that whole lesion diffusivity measurement is not always superior to ROI analysis [25, 44].

The ability of ADC to predict glioma subtypes and optimum thresholds may be subject to ROI placement technique with previous research focusing on minimum $\mathrm{ADC}$ value analysis: Xing et al. showed a statistical correlation between ADC and IDH status using a multiple $(\geq 5)$ ROI technique with the mean of the lowest ADC measurement chosen as minimum ADC in consensus [45]. In a similar fashion, a previous DTI study for IDH typing used multiple ROI placements and a two-reader consensus method to obtain minimum ADC values [24].

As a reference ROI, we chose the centrum semiovale for its potentially greater reproducibility compared to a 'mirror' ROI [45], because this could be influenced by tumour location. We
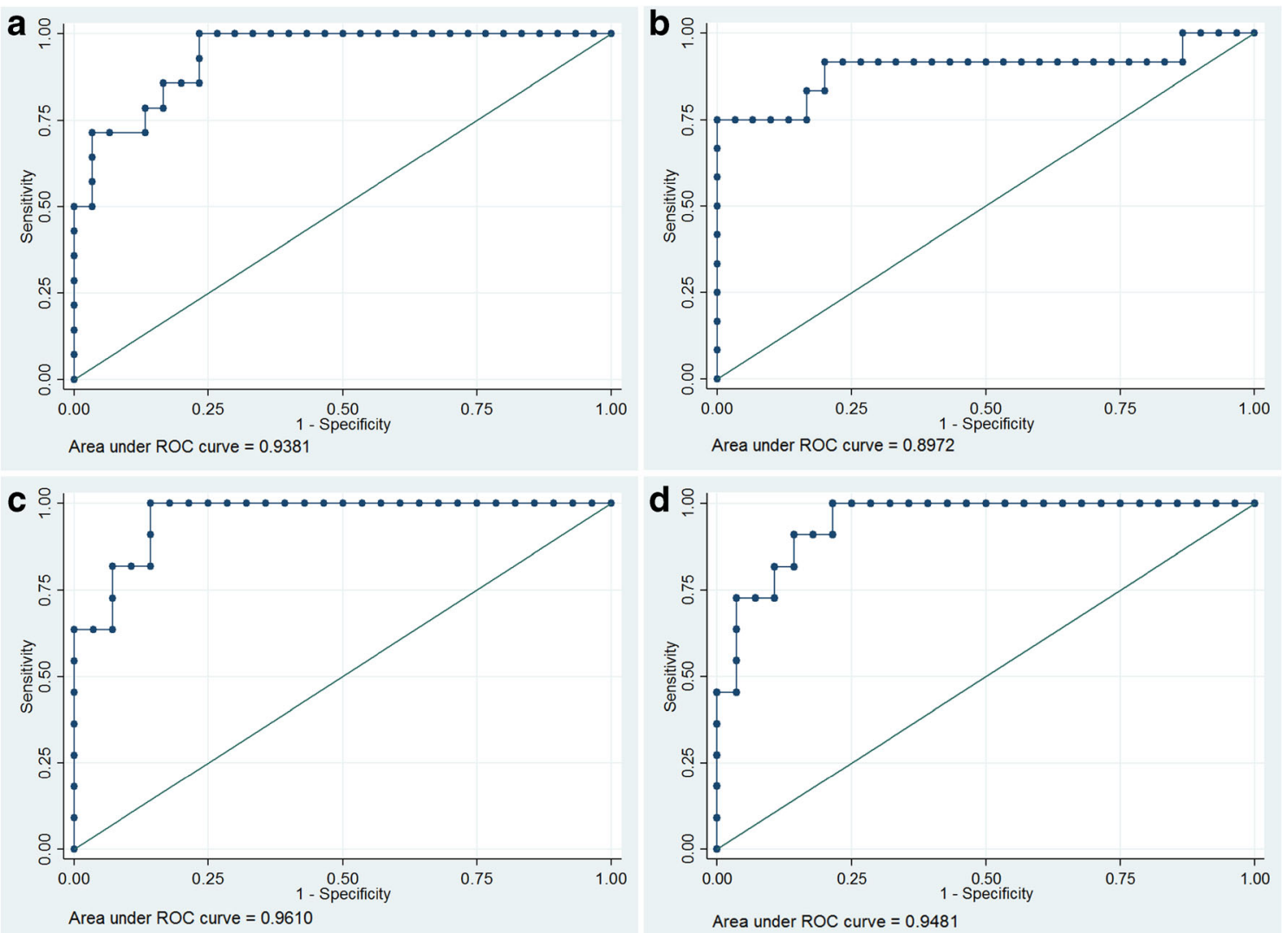

Fig. 5 ROC curves for the a whole tumour $\mathrm{ADC}_{\text {mean }}\left(\mathrm{VOI}_{\text {tum }}\right)$, $\mathbf{b}$ whole tumour $\mathrm{ADC}_{\text {ratio }}$, $\mathbf{c}$ single slice PACS_ADC $\mathrm{C}_{\text {ratio }}$ observer 1 and $\mathbf{d}$ observer 2 
avoided the internal capsule [24], which is a smaller structure and more difficult to locate by an untrained rater.

Lee et al. found ADC mean and ADC histograms useful for IDH typing of WHO grade III and IV gliomas [46]. However, for glioblastoma IDH typing alone, a recent study identified no difference in ADC values [47]. In Tan et al.'s study of grade II-IV gliomas, the accuracy of ADC for IDH typing decreased with higher grade, which may reflect greater lesion heterogeneity [24]. It is probable that in such circumstances advanced diffusion acquisitions (e.g. DKI or multi- $b$-value imaging) could provide greater tissue microstructural information.

The good performance of the single slice ROI technique in IDH typing of non-enhancing lower grade gliomas was unexpected, but is highly relevant. It implies that such easy-toperform measurements could be incorporated into clinical reports, complementing advanced MR modalities such as perfusion and 2HG spectroscopy [48, 49] pending tissue diagnosis. The origin of data from 18 MRI systems could represent a limitation of this study, but reflects clinical reality. The fact that significant separation of glioma subtypes could be obtained from this dataset further underscores the robustness of ADC.

It remains unknown why intermediate $\mathrm{ADC}$ values were observed in the 1p19q co-deleted gliomas, despite their best prognosis. This result is consistent with published data on intermediate diffusivity in oligodendroglioma; interestingly this tumour subtype may also mimic malignant gliomas on MR perfusion studies [39, 50].

In summary, the results from this study suggest that for newly diagnosed non-enhancing gliomas with ADC ratio values of 1.8 or less, further investigation with consideration of early tissue diagnosis is advisable given an increased risk of $\mathrm{IDH}^{\mathrm{wt}}$ molecular status.

\section{Conclusions}

ADC measurement appears to be a simple and powerful method for molecular subtyping of non-enhancing WHO II-III gliomas, specifically to identify $\mathrm{IDH}^{\mathrm{wt}}$ neoplasms. In our patient cohort, a two-dimensional ROI measurement in the largest lesion cross-section appeared representative of the entire tumour with comparable results.

Funding This study received no specific funding, but was supported by the National Institute for Health Research University College London Biomedical Research Centre.

\section{Compliance with ethical standards}

Guarantor The scientific guarantor of this publication is Stefanie Thust.

Conflict of interest The authors of this manuscript declare no relationships with any companies whose products or services may be related to the subject matter of the article.
Statistics and biometry One of the authors (C.T. MD PhD MSc Medical Statistics) has significant statistics expertise.

Informed consent Written informed consent was waived by the institutional review board.

Ethical approval Institutional review board approval was obtained.

\section{Methodology}

- retrospective

- diagnostic study/observational

- performed at one institution

Open Access This article is distributed under the terms of the Creative Commons Attribution 4.0 International License (http:// creativecommons.org/licenses/by/4.0/), which permits unrestricted use, distribution, and reproduction in any medium, provided you give appropriate credit to the original author(s) and the source, provide a link to the Creative Commons license, and indicate if changes were made.

\section{References}

1. Pierallini A, Bonamini M, Bozzao A et al (1997) Supratentorial diffuse astrocytic tumours: proposal of an MRI classification. Eur Radiol 7:395-399

2. Watanabe M, Tanaka R, Takeda N (1992) Magnetic resonance imaging and histopathology of cerebral gliomas. Neuroradiology 34 : 463-469

3. Tervonen O, Forbes G, Scheithauer BW, Dietz MJ (1992) Diffuse "fibrillary" astrocytomas: correlation of MRI features with histopathologic parameters and tumor grade. Neuroradiology 34:173178

4. Ideguchi M, Kajiwara K, Goto $\mathrm{H}$ et al (2015) MRI findings and pathological features in early-stage glioblastoma. J Neurooncol 123:289-297

5. Cuccarini V, Erbetta A, Farinotti M et al (2016) Advanced MRI may complement histological diagnosis of lower grade gliomas and help in predicting survival. J Neurooncol 126:279-288

6. Olar A, Raghunathan A, Albarracin CT et al (2012) Absence of IDH1-R132H mutation predicts rapid progression of nonenhancing diffuse glioma in older adults. Ann Diagn Pathol 16:161-170

7. Baehring JM, Bi WL, Bannykh S et al (2007) Diffusion MRI in the early diagnosis of malignant glioma. J Neurooncol 82:221-225

8. Ginsberg LE, Fuller GN, Hashmi M et al (1998) The significance of lack of MR contrast enhancement of supratentorial brain tumors in adults: histopathological evaluation of a series. Surg Neurol 49: 436-440

9. Dang L, White DW, Gross S et al (2009) Cancer-associated IDH1 mutations produce 2-hydroxyglutarate. Nature 462:739-744

10. Yan H, Parsons DW, Jin G et al (2009) IDH1 and IDH2 mutations in gliomas. N Engl J Med 360:765-773

11. Cancer Genome Atlas Research Network, Brat DJ, RGW V et al (2015) Comprehensive, integrative genomic analysis of diffuse lower-grade gliomas. N Engl J Med 372:2481-2498

12. Louis DN, Perry A, Burger P et al (2014) International Society of Neuropathology-Haarlem consensus guidelines for nervous system tumor classification and grading. Brain Pathol Zurich Switz 24: 429-435

13. Eckel-Passow JE, Lachance DH, Molinaro AM et al (2015) Glioma groups based on $1 \mathrm{p} / 19 \mathrm{q}, \mathrm{IDH}$, and TERT promoter mutations in tumors. N Engl J Med 372:2499-2508 
14. Abudumijiti A, Chan AK-Y, Shi Z et al (2017) Adult IDH wild-type lower-grade gliomas should be further stratified. Neuro Oncol. https://doi.org/10.1093/neuonc/nox078

15. Suzuki Y, Shirai K, Oka K et al (2010) Higher pAkt expression predicts a significant worse prognosis in glioblastomas. J Radiat Res (Tokyo) 51:343-348

16. Reuss DE, Sahm F, Schrimpf D et al (2015) ATRX and IDH1$\mathrm{R} 132 \mathrm{H}$ immunohistochemistry with subsequent copy number analysis and IDH sequencing as a basis for an "integrated" diagnostic approach for adult astrocytoma, oligodendroglioma and glioblastoma. Acta Neuropathol (Berl) 129:133-146

17. Hartmann C, Hentschel B, Wick W et al (2010) Patients with IDH1 wild type anaplastic astrocytomas exhibit worse prognosis than IDH1-mutated glioblastomas, and IDH1 mutation status accounts for the unfavorable prognostic effect of higher age: implications for classification of gliomas. Acta Neuropathol (Berl) 120:707-718

18. Darlix A, Deverdun J, Menjot de Champfleur N et al (2017) IDH mutation and $1 \mathrm{p} 19 \mathrm{q}$ codeletion distinguish two radiological patterns of diffuse low-grade gliomas. J Neurooncol 133:37-45

19. Metellus P, Coulibaly B, Colin C et al (2010) Absence of IDH mutation identifies a novel radiologic and molecular subtype of WHO grade II gliomas with dismal prognosis. Acta Neuropathol (Berl) 120:719-729

20. Patterson DM, Padhani AR, Collins DJ (2008) Technology insight: water diffusion MRI-a potential new biomarker of response to cancer therapy. Nat Clin Pract Oncol 5:220-233

21. Zhang L, Min Z, Tang M et al (2017) The utility of diffusion MRI with quantitative $\mathrm{ADC}$ measurements for differentiating high-grade from low-grade cerebral gliomas: Evidence from a meta-analysis. J Neurol Sci 373:9-15

22. Hempel J-M, Bisdas S, Schittenhelm J et al (2017) In vivo molecular profiling of human glioma using diffusion kurtosis imaging. J Neurooncol 131:93-101

23. Xiong J, Tan W, Wen J et al (2016) Combination of diffusion tensor imaging and conventional MRI correlates with isocitrate dehydrogenase $1 / 2$ mutations but not $1 \mathrm{p} / 19 \mathrm{q}$ genotyping in oligodendroglial tumours. Eur Radiol 26:1705-1715

24. Tan WL, Huang WY, Yin B et al (2014) Can diffusion tensor imaging noninvasively detect IDH1 gene mutations in astrogliomas? A retrospective study of 112 cases. AJNR Am J Neuroradiol 35: 920-927

25. Han X, Suo S, Sun Y et al (2017) Apparent diffusion coefficient measurement in glioma: Influence of region-of-interest determination methods on apparent diffusion coefficient values, interobserver variability, time efficiency, and diagnostic ability. J Magn Reson Imaging JMRI 45:722-730

26. Pipe J (2009) Chapter 2 - pulse sequences for diffusion-weighted MRI. In: Johansen-Berg H, Behrens TEJ (eds) Diffusion MRI. Academic Press, San Diego, pp 11-35

27. Jenkinson M, Beckmann CF, Behrens TEJ et al (2012) FSL. NeuroImage 62:782-790

28. Yushkevich PA, Piven J, Hazlett HC et al (2006) User-guided 3D active contour segmentation of anatomical structures: significantly improved efficiency and reliability. NeuroImage 31:1116-1128

29. Jenkinson M, Bannister P, Brady M, Smith S (2002) Improved optimization for the robust and accurate linear registration and motion correction of brain images. NeuroImage 17:825-841

30. Jenkinson M, Smith S (2001) A global optimisation method for robust affine registration of brain images. Med Image Anal 5: 143-156

31. Seiz M, Freyschlag CF, Schenkel S et al (2011) Management of patients with low-grade gliomas - a survey among German neurosurgical departments. Cent Eur Neurosurg 72:186-191

32. Khan OH, Mason W, Kongkham PN et al (2016) Neurosurgical management of adult diffuse low grade gliomas in Canada: a multi-center survey. J Neurooncol 126:137-149
33. Karavaeva E, Harris RJ, Leu K et al (2015) Relationship between [18F]FDOPA PET uptake, apparent diffusion coefficient (ADC), and proliferation rate in recurrent malignant gliomas. Mol Imaging Biol 17:434-442

34. Fudaba H, Shimomura T, Abe T et al (2014) Comparison of multiple parameters obtained on $3 \mathrm{~T}$ pulsed arterial spin-labeling, diffusion tensor imaging, and MRS and the Ki-67 labeling index in evaluating glioma grading. AJNR Am J Neuroradiol 35:2091-2098

35. Ellingson BM, Malkin MG, Rand SD et al (2010) Validation of functional diffusion maps (fDMs) as a biomarker for human glioma cellularity. J Magn Reson Imaging JMRI 31:538-548

36. Higano S, Yun X, Kumabe T et al (2006) Malignant astrocytic tumors: clinical importance of apparent diffusion coefficient in prediction of grade and prognosis. Radiology 241:839-846

37. Miloushev VZ, Chow DS, Filippi CG (2015) Meta-analysis of diffusion metrics for the prediction of tumor grade in gliomas. AJNR Am J Neuroradiol 36:302-308

38. Zulfiqar M, Yousem DM, Lai H (2013) ADC values and prognosis of malignant astrocytomas: does lower ADC predict a worse prognosis independent of grade of tumor? A meta-analysis. AJR Am J Roentgenol 200:624-629

39. Cui Y, Ma L, Chen X et al (2014) Lower apparent diffusion coefficients indicate distinct prognosis in low-grade and high-grade glioma. J Neurooncol 119:377-385

40. Khayal IS, Vandenberg SR, Smith KJ et al (2011) MRI apparent diffusion coefficient reflects histopathologic subtype, axonal disruption, and tumor fraction in diffuse-type grade II gliomas. Neuro Oncol 13:1192-1201

41. Tozer DJ, Jäger HR, Danchaivijitr N et al (2007) Apparent diffusion coefficient histograms may predict low-grade glioma subtype. NMR Biomed 20:49-57

42. Clark K, Voronovich Z, Horbinski C (2013) How molecular testing can help (and hurt) in the workup of gliomas. Am J Clin Pathol 139: 275-288

43. Leu K, Ott GA, Lai A et al (2017) Perfusion and diffusion MRI signatures in histologic and genetic subtypes of WHO grade II-III diffuse gliomas. J Neurooncol. https://doi.org/10.1007/s110600172506-9

44. Arponen O, Arponent O, Sudah M et al (2015) Diffusion-weighted imaging in 3.0 Tesla breast MRI: diagnostic performance and tumor characterization using small subregions vs. whole tumor regions of interest. PloS One 10:e0138702

45. Xing Z, Yang X, She D et al (2017) Noninvasive assessment of IDH mutational status in World Health Organization grade II and III astrocytomas using DWI and DSC-PWI combined with conventional MR imaging. AJNR Am J Neuroradiol 38:1138-1144

46. Lee S, Choi SH, Ryoo I et al (2015) Evaluation of the microenvironmental heterogeneity in high-grade gliomas with IDH1/2 gene mutation using histogram analysis of diffusion-weighted imaging and dynamic-susceptibility contrast perfusion imaging. J Neurooncol 121:141-150

47. Yamashita K, Hiwatashi A, Togao O et al (2016) MR imagingbased analysis of glioblastoma multiforme: estimation of IDH1 mutation status. AJNR Am J Neuroradiol 37:58-65

48. Kickingereder P, Sahm F, Radbruch A et al (2015) IDH mutation status is associated with a distinct hypoxia/angiogenesis transcriptome signature which is non-invasively predictable with rCBV imaging in human glioma. Sci Rep 5:16238

49. Andronesi OC, Rapalino O, Gerstner E et al (2013) Detection of oncogenic IDH1 mutations using magnetic resonance spectroscopy of 2-hydroxyglutarate. J Clin Invest 123:3659-3663

50. Lev MH, Ozsunar Y, Henson JW et al (2004) Glial tumor grading and outcome prediction using dynamic spin-echo MR susceptibility mapping compared with conventional contrast-enhanced MR: confounding effect of elevated rCBV of oligodendrogliomas [corrected]. AJNR Am J Neuroradiol 25:214-221 